\title{
GUERRA DE CANUDOS NA REVISTA ILLUS- TRADA: A REPÚBLICA COMO DISCURSO
}

\section{LA GUERRA DE CANUDOS EM LA REVISTA ILLUS- TRADA: LA REPÚBLICA COMO DISCURSO}

Yuria Santamaria Pismel ${ }^{1}$

Resumo: A partir das edições da Revista Illustrada, criada por Angelo Agostini em 1876, pretende-se analisar as passagens de 1897, em que é mencionada a Guerra de Canudos. A proposta é identificar os elementos do discurso dos editores da revista sobre o conflito, em seu último ano, 1897. A Revista Illustrada era editada no Rio de Janeiro, centro político, militar e cultural do período, evocando um discurso que se coloca contra o movimento popular de Canudos. Pretende-se analisar tal posicionamento, considerando o contexto social, cultural e político da revista. O recorte temporal escolhido deve-se à complexidade dos acontecimentos, em que saíram vitoriosas as forças militares oficiais, quando em outubro de 1897, o arraial foi arrasado e incendiado. Buscar-se-á compreender a análise da revista em relação à Guerra de Canudos, como difusora do discurso oficial.

Palavras-chave: Guerra de Canudos; Revista Illustrada; Angelo Agostini; Primeira República.

Resumen: A partir de las ediciones de la Revista Illustrada, creada por Angelo Agostini em 1876, se pretende analizar los pasajes de 1897, en que es mencionada la Guerra de Canudos. La propuesta es identificar los elementos del discurso de los editores de la revista sobre el conflicto, en su último año, 1897. El destaque de Rio de Janeiro como centro político, militar y cultural del periodo justifica el hecho de escoger la Revista Illustrada, que se coloca en contra el movimiento popular de Canudos.

${ }^{1}$ Aluna de graduação em História - licenciatura e Bacharelado na Universidade Federal do Paraná. Orientada pelo Professor Doutor Marcos Gonçalves. Endereço para o currículo lattes: http://lattes.cnpq.br/5502232500135724 
Se pretende analizar tal posición, considerando el contexto social, cultural y político de la revista. El recorte temporal escogido se debe a la complejidad de los acontecimientos, en que salieron victoriosas las fuerzas militares oficiales, cuando en octubre de 1897 Canudos fué destruído e incendido. Se buscará comprender el análisis de la revista en relación a la Guerra de Canudos, como difusora del discurso oficial.

Palabras clave: Guerra de Canudos; Revista Illustrada; Angelo Agostini; Primera República.

\section{Introdução}

O presente trabalho tem como objetivo analisar o relato produzido pela Revista Illustrada ${ }^{2}$ sobre o último ano da Guerra de Canudos, 1897. Foram selecionadas as passagens das edições do mesmo ano que expressam o posicionamento da revista e seus argumentos centrais, expostos através de informações escritas ou pictóricas. Portanto, pretende-se discernir os principais elementos recorrentes no discurso dos editores sobre o conflito. Serão consideradas as particularidades dos editores e do local em que a revista era produzida, bem como o contexto histórico, social e político que marcou a última década do século XIX, como um período de instabilidade característico do processo de consolidação da Primeira República.

A Revista Illustrada circulou na imprensa carioca de 1876 a 1898. Inicialmente, era uma publicação semanal, em que veiculavam notícias políticas retratadas em um tom satírico. Angelo Agostini, seu fundador,

\footnotetext{
${ }^{2}$ Jornal Revista Illustrada. Periódico editado por Angelo Agostini (1876-1889) e Pereira Neto (1889-1898). Rio de Janeiro, 1876-1898. Edições 00727(jan.1897), 00728(fev.-1897), 00729(mar.-1897), 00730(abr.1897), 00731(set.1897), 00733(out.1897), 00734(nov./dez.?-1897). Disponível online para consulta na Hemeroteca Digital Brasileira/ Biblioteca Nacional Digital.
} 
após participar como colaborador em diversas revistas de São Paulo e do Rio de Janeiro, decidiu criar em 1876 uma publicação própria, com o intuito de divulgar suas interpretações acerca do cenário político brasileiro. Os temas centrais em seus primeiros anos eram a defesa da abolição e a crítica à monarquia, traços que marcaram o discurso da revista em todo o seu percurso. A revista passou por duas fases. Na primeira, de 1876 a 1889, esteve sob o comando de Angelo Agostini, período em que alcançou seu auge e reconhecimento. Em 1889, com o retorno de Agostini para a Itália, a revista ficou a cargos do cartunista Pereira Neto, embora Agostini continuasse a contribuir esporadicamente. Durante essa segunda fase, não ocorreram grandes transformações na abordagem dos temas. Sob o comando de Pereira Neto, a revista passou a aceitar anúncios, a partir de janeiro de 1889.

A partir da seleção das fontes documentais, pretende-se analisar o discurso da revista sobre os sertanejos de Canudos em oposição à República, personificada nas ilustrações como uma figura feminina esbelta, contrastando com o retrato rústico de Antônio Conselheiro. A figura assemelha-se, nos traços e na postura, à Marianne, representante da República Francesa, principalmente à obra "A liberdade guiando o povo", de Eugène Delacroix. A utilização da alegoria feminina aos moldes neoclássicos para representar a República é analisada por José Murilo de Carvalho (Carvalho, 2009: 75-96), em sua obra "A Formação das Almas". Segundo o autor, na França, o uso da imagem feminina associada à República opunha-se à imagem do rei e da Monarquia. A figura feminina republicana, popularizada na França durante a Terceira República 
com a denominação de Marianne, trazia consigo o ideal de liberdade, revolução e cidadania, inspirando artistas e intelectuais da época. Portanto, os republicanos brasileiros apropriam-se desse símbolo para representar a República recém fundada no Brasil. De acordo com José Murilo de Carvalho (Carvalho, 2009: 75-96), tal apropriação republicana deu-se inicialmente através do trabalho dos cartunistas da imprensa periódica, que sendo em sua maioria simpatizantes do novo regime, auxiliaram a criar símbolos que definissem a República. O próprio autor ressalta o caso de Angelo Agostini e Pereira Neto na Revista Illustrada como exemplos da construção dessa imagem, no que tange ao trabalho artístico realizado pelos cartunistas em 1888 e 1889. Carvalho destaca ainda a Revista Illustrada enquanto estabelecedora de um modelo que serviu às outras revistas do mesmo período, no que se refere à representação feminina republicana. Apresenta-se um paralelo entre os valores libertários promovidos pela República Brasileira, recém-inaugurada, e a República Francesa. O contraste entre a figura feminina e a representação de Antônio Conselheiro, denota a oposição entre os próprios valores republicanos e monárquicos expressa na Revista Illustrada, bem como um posicionamento dos editores do periódico. Tratando dos aspectos historiográficos, vale relembrar que a pesquisadora Jacqueline Hermann (Hermann, 2003: 121-160) aponta que somente a partir da década de 1960 os movimentos messiânicos brasileiros passaram a ser estudados como objeto de análise. Nesse sentido, são recentes os estudos que atentam para a relativização da oposição entre o soldado legalista e o sertanejo, recurso que auxilia na definição do movimento de Canudos como 
uma manifestação social antirrepublicana, restauradora e fanática. Como discussão inicial, levamos em consideração a análise da pesquisadora Janice Theodoro (Theodoro, 1997: 119-133) e de uma prédica de Antônio Conselheiro de 1895 (Bonavides; Amaral, 2002: 445-450).

Janice Theodoro afirma que Antônio Conselheiro soube utilizarse da oratória para criar um discurso que transformasse a República em “uma espécie de demônio que deveria ser combatido" (Theodoro, 1997: 126), mas que esse não era o tema central de seu discurso. Embora as críticas à República sejam evidenciadas no discurso, a preocupação central de Conselheiro girava em torno da manutenção da religião. $\mathrm{O}$ caráter profético de suas pregações carregadas de citações bíblicas e sua visão milenarista dos fatos auxiliou na repercussão do movimento. A comunidade proposta por Antonio Conselheiro pretendia mais um distanciamento que uma aproximação às causas monárquicas. É o que afirma a autora, que propõe a relativização ao considerar o movimento de Canudos como restaurador e antirrepublicano, na medida em que é necessário levar em conta a religiosidade da população como um elemento aglutinador e promotor de uma identidade.

A crítica de Antônio Conselheiro à República presente em um de deus discursos de 1895 exemplifica tais questões (Bonavides; Amaral, 2002: 445-450). O tema assume centralidade no decorrer do discurso, devido à preocupação em defender uma moral religiosa católica. Já no primeiro parágrafo, a República é tratada como "um grande mal para o Brasil", pois trouxe o "extermínio da religião", sendo, portanto, "o ludíbrio da tirania para os fiéis" (Ibid.: 445). O discurso de Conselheiro 
aponta para a importância de preservar a "santa religião", sendo o novo regime o inimigo a ser combatido, já que provocara a desestruturação dos princípios básicos religiosos. Nesse sentido, cabe destacar as menções ao casamento civil, visto por Conselheiro como uma afronta ao poder divino que reflete com clareza a incredulidade dos republicanos, já que o casamento é de responsabilidade da santa igreja. Em tom profético, Antônio Conselheiro afirma:

A República há de cair por terra para confusão daquele que concebeu tão horrorosa ideia. Convençam-se, republicanos, que não hão de triunfar porque a sua causa é filha da incredulidade [...] Dá a Deus o que é de Deus, dá a César o que é de César. Mas este sublime sentimento não domina no coração do presidente da República, que a seu talante quer governar o Brasil. (Ibid.: 448-449)

Portanto, o discurso de Antônio Conselheiro, baseado em argumentos de proteção à fé cristã, assume a crítica ao novo regime como principal prerrogativa para combater os infiéis da santa religião, assumindo um caráter social e popular. A ênfase no caráter antirrepublicano e monarquista dos sertanejos feita pelo governo oficial, pode ser compreendida como uma resposta republicana às críticas ao novo regime. Considerando a instabilidade social da Primeira República, o rápido crescimento territorial e populacional do arraial de Canudos é visto pelo governo oficial como uma ameaça ao próprio regime, ainda em processo de consolidação.

\section{A Revista Illustrada como documento histórico de uma época}


A imprensa contemporânea à reação de Canudos interpretava o movimento como uma grave ameaça à República, alegando sua tendência monarquista no sertão baiano. Não havia um espaço na imprensa dedicado às causas de Antônio Conselheiro, como afirma Gilberto Maringoni (Maringoni, 2006: 221-239). O autor relata que particularmente no Rio de Janeiro, a imprensa do final do século XIX adquiriu um caráter acentuado de aversão às causas populares de Canudos. Como centro político, econômico e administrativo do Brasil, o Rio de Janeiro representava um polo importante de irradiação, e, tratando-se da imprensa, como centro difusor de um imaginário social modernizador.

De acordo com Nicolau Sevcenko (Sevcenko, 1998: 7-48), nas últimas décadas do século XIX, a tentativa de disseminar o avanço capitalista, modernizador e civilizador causou um impacto sobre as sociedades tradicionais, desestabilizando-as. No Brasil, a geração intelectual dos anos 1870, busca novas bases ideológicas inspiradas nas diretrizes europeias e estadunidenses, tais como o cientificismo, o darwinismo social e o positivismo. A Abolição, a Proclamação da República e a entrada de imigrantes estrangeiros mobilizavam as elites intelectuais a repensar os aspectos econômicos e sociais a partir da nova configuração do trabalho e dos debates sobre a identidade brasileira. Com base nos preceitos da modernização em ascensão no Brasil, as mudanças jurídicoinstitucionais promovidas pelo governo abalaram as sociedades tradicionais, que não eram representadas pelo novo regime.

Rodrigo Lacerda (Lacerda, 1997: 21 - 39) reforça essa ideia afirmando que com a República e o aumento da autonomia dos estados, 
uma parcela maior dos impostos passou a ser direcionada aos municípios. A arrecadação de forma direta abalou as comunidades de classes sociais mais pobres, como é o caso da região do sertão baiano. A reação das sociedades tradicionais aos impulsos modernizadores é entendida pelo governo republicano como uma aversão à República, como é possível perceber pelo discurso da revista. A imagem construída dos conselheiristas como conspiradores monarquistas coloca-se como uma justificativa para acirrar as investidas contra a população de Canudos. Ao serem tratados como "fanáticos religiosos", os conselheiristas apresentavam-se como uma ameaça não só para o Estado, mas também para a hegemonia da Igreja Católica.

Inserido nessa estrutura política, social e intelectual, encontra-se o caricaturista Angelo Agostini. Por ser ele o fundador e criador das bases ideológicas, políticas e sociais que norteavam a revista, enfocaremos na análise de Agostini mais profundamente, em oposição à Pereira Neto, que, ao dar continuidade à revista, conservou a maioria das propostas ideológicas da revista, como explica Marcelo de Souza Magalhães (Magalhães, 2007: 1-29). O italiano conviveu com a nova elite intelectual brasileira e desenvolveu suas ideias alinhadas com o pensamento abolicionista de Joaquim Nabuco, embora faça "uma campanha com roteiro próprio, nas páginas de sua revista", como afirma Maringoni (Maringoni, 2006: 226). Em seu artigo intitulado Angelo Agostini e o Massacre de Canudos, o autor buscou explicar como Agostini, sendo defensor das causas abolicionistas, opôs-se aos conselheiristas. O autor constata que o caricaturista era defensor da causa abolicionista por um viés elitista e 
racista, em prol do desenvolvimento da República. Portanto, apesar do seu posicionamento a favor da abolição ser frequentemente associado à construção de uma imagem como defensor das causas populares, o seu projeto abolicionista gira em torno da libertação dos escravos, e não na preocupação de inserção destes na sociedade no contexto de pósabolição.

José Murilo de Carvalho ressalta em seu livro "Os Bestializados" (Carvalho, 1991: 15-41) as transformações e turbulências pelas quais passou o Rio de Janeiro na primeira década da República. Além de ser a capital da República, era a maior cidade, bem como um centro importante no que tange ao aspecto econômico, político e cultural. Portanto, segundo Carvalho, as transformações recorrentes do processo de abolição e da proclamação da República fizeram-se sentir, transparecendo as dificuldades e entraves da nova realidade. Os posicionamentos políticos criaram diversas vertentes ideológicas, influenciadas pelas correntes intelectuais provenientes da Europa, como o positivismo, o liberalismo e o anarquismo, sendo que os tensionamentos políticos e sociais geraram diversas rebeliões e inquietações, não só na capital, mas em diversas regiões do país, e que repercutiram na capital. É o caso do movimento de Canudos, em que os preceitos modernizadores e republicanos entram em choque com uma conjuntura social e ideológica estabelecida, gerando um conflito social, cultural e político. Além do conflito entre as sociedades tradicionais e o Estado republicano, como destaca Jacqueline Hermann (Hermann, 2003: 121-160), apresentava-se o conflito religioso 
entre o catolicismo rústico, que mesclava tradições e ritos populares à crença, e o catolicismo oficial.

Nesse sentido, a escolha do recorte espacial a ser analisado, no caso, a Revista Illustrada enquanto periódico em circulação no Rio de Janeiro, justifica-se pela tentativa de compreender a construção do discurso defensor da República, ainda em processo de consolidação, em oposição ao passado monárquico representado nas retratações dos conselheiristas. A escolha de um periódico do Rio de Janeiro deve-se ao papel decisivo da cidade na Guerra de Canudos, que como centro administrativo concentrava as principais forças do exército, e enviou tropas ao sertão baiano, em suas investidas para combater os "inimigos da República". As inovações estilísticas e estéticas, principalmente o efeito visual das caricaturas de Angelo Agostini, e posteriormente, Pereira Neto, são comentadas por Carlos Costa (Costa, 2012: 315-363). A reportagem enquanto recurso aparece como uma das marcas de Agostini, em oposição ao jornalismo praticado no período. Já na primeira edição da revista, em 1876, é interessante observar a utilização de um jogo audiovisual nas caricaturas, bem como a presença de duendes e arlequins, que segundo Costa, personificam os ajudantes dos editores. Costa enfatiza Revista Illustrada como "recordista de vendas na América Latina", demonstrando assim sua repercussão e aceitação.

Com a Abolição e a Proclamação da República, os principais eixos temáticos deixaram de ser tão debatidos no cenário político, e, portanto, aos poucos a revista foi perdendo espaço e leitores, o que conduziu ao encerramento de suas atividades em 1898. Em seu livro A revista 
do Brasil do século XIX, Carlos Costa (Costa, 2012: 315-363), afirma que em seus últimos anos de existência, a revista foi perdendo credibilidade e importância, em partes, pois as discussões acerca da liberdade de imprensa e da monarquia deixaram de ser veiculadas. Embora as causas abolicionistas e antimonárquicas tenham deixado de ocupar a posição central no cenário político, continuaram a orientar politicamente as publicações. A periodicidade da revista diminuiu gradativamente, passando a ser publicada mensalmente (ao invés de semanalmente), como é o caso do ano em 1897. A revista possuía em média de sete a oito páginas cada edição, tratando de acontecimentos políticos e cotidianos por um viés satírico e caricaturado. A primeira página apresenta um tema e uma ilustração em destaque. Nas páginas seguintes, há uma mescla entre notícias comentadas, cartas de opinião, contos, capítulos de romances, charges, caricaturas, ilustrações e retratos de personagens considerados politicamente importantes no contexto republicano.

Desde 1885, a revista constituía-se como uma publicação semanal com oito páginas em média, veiculando charges e textos, contando com 739 números até 1898, quando encerrou suas atividades. Nem todas as seções da revista eram permanentes, embora fosse respeitada uma estrutura. Merece destaque o Editorial, que dava continuidade ao assunto da capa, e costumava apresentar textos concisos e doutrinários, na medida em que expunham as visões dos autores. É recorrente uma seção reservada aos comentários sobre a Revista Illustrada veiculados em outros periódicos, bem como agradecimentos às menções. Quanto aos valores, Carlos Costa (Costa, 2012: 315-363) afirma: 
A seguir, os preços das assinaturas: $16 \$ 000$ anual; $9 \$ 000$ semestral; e 5\$000 trimestral. Nas províncias, o preço sobre para $20 \$ 000$ anual; $11 \$ 000$ semestral; e $\$ 500$ o número avulso. Como já se disse, o preço do exemplar avulso era praticamente o mesmo praticado por todas as semanais ilustradas do período [...] comparado com o preço dos jornais diários. "(COSTA, 2012, pág. 332)

Atentamos que nem todas as caricaturas e ilustrações contidas possuem assinatura do seu autor. Como assinala Marcelo de Souza Magalhães (Magalhães, 2007: 1-29) em seu artigo Crônicas da vida na cidade: o cotidiano da política nas charges da Revista Illustrada (18921898), tratando-se da década de 1890, os traços de Angelo Agostini e de Pereira Neto se confundem, e pela falta de identificação, não é possível confirmar a autoria de cada ilustração. O autor ressalta que Pereira Neto assinou muito poucas caricaturas na sua carreira profissional na revista. Contudo, considerando que em 1895 Angelo Agostini lança uma nova revista denominada Don Quixote, presume-se que as publicações a partir da Revista Illustrada tenham sido produzidas principalmente por Pereira Neto. Quanto aos artigos, nem todos possuem assinatura. As publicações escritas que estão assinadas aparecem muitas vezes com as siglas dos nomes. Considerando a proposta de análise do presente trabalho como a tentativa de estabelecer uma relação entre a Guerra de Canudos e a visão da revista sobre o conflito, tal questão não será tratada com profundidade. $\mathrm{O}$ enfoque será em entender o conflito pelas imagens que a Revista Illustrada construiu sobre os sertanejos nas publicações de 1897. 


\section{A Guerra de Canudos na Revista Illustrada}

Já na primeira edição do ano de 1897 (Edição 727, Ano 22 - Jan. 1897), fica perceptível a oposição entre o governo republicano e seus adeptos, e o movimento de Canudos. Na página 3, o coronel Moreira César, que se preparava para comandar a Terceira Expedição oficial contra Canudos, é apresentado como exemplo de "herói da República". A continuidade do discurso ocorre na página seguinte, com a apresentação de uma caricatura em forma de quadrinhos. Antonio Conselheiro é representado como um senhor barbudo e de traços rústicos "pintando o diabo", expressão contida na legenda. A construção da imagem de Conselheiro se dá através da sua representação como um indivíduo que atua com violência sem precedentes, radical e fanático. A legenda exemplifica: " [...] atirando-se como gato a bofes a todos aquelles que não comungam com as suas idéias fanáticas". A imagem de Conselheiro é construída como defensor de um "engrossamento restaurador" do antigo regime monárquico. Na sequência, a terceira imagem sobre Canudos estabelece o embate com a República, no qual Antonio Conselheiro é acusado de dirigir-se à República com as seguintes palavras “- Alto lá! d'aqui não passarás...". No final da legenda, ainda é necessário destacar a atitude do governo frente a essa "ameaça", com a menção à Terceira Expedição que tinha como líder Moreira César. O general e os oficiais do exército mais uma vez são vistos como os defensores e heróis em prol da causa republicana.

Na terceira página da edição de fevereiro (Edição 728, Ano 22 Fev. 1897), em uma breve nota, é criado um discurso satírico sobre An- 
tônio Conselheiro, em que a revista se refere a ele, ironicamente, com a expressão "o heróe de Canudos”. Na página seguinte, novamente a ironia aparece juntamente com um humor disfarçado, agora através de uma ilustração que retrata Antonio Conselheiro entre quatro canhões que apontam para ele. A revista assume o tom confiante e encorajado frente aos esforços de preparação da Terceira Expedição. Conselheiro é chamado de "fanático sebastianista" 3 , em uma associação do arraial de Canudos com o messianismo religioso. Na mesma página, na imagem ao lado, como que contrastando e colocando em embate as duas questões, foi colocada a Homenagem à República e ao sexto aniversário da Constituição Federal.

Dando continuidade à questão religiosa, na página 6, é mencionada a Missão de Frei Monte Marciano pelos sertões da Bahia rumo às terras de Conselheiro, notícia veiculada originalmente no periódico denominado República, o que mostra o diálogo entre as duas publicações. Portanto, alude-se ao fato de Canudos enquanto um movimento que ameaçava simultaneamente a hegemonia da Igreja e do Estado. Como afirma Jacqueline Hermann (Hermann, 2003: 121-160), com o início da República, a Igreja passou por um processo de adaptação às novas imposições feitas pela nova ordem vigente. Por outro lado, a perda de poder das autoridades religiosas trouxe dificuldade em lidar com as reações populares dos ditos "movimentos messiânicos", como definido

${ }^{3}$ Sobre o processo de formação do sebastianismo enquanto um movimento profético, consultar: HERMANN, Jacqueline. No reino do desejado: a construção do sebastianismo em Portugal, séculos XVI e XVII. São Paulo, Companhia das Letras, 1998. 
pela autora. Portanto, a missão religiosa que se dirigiu até Canudos, citada pela revista, insere-se nesse contexto de adaptação da Igreja ao novo regime, e consequentemente, à tentativa de fortalecer a autoridade eclesiástica abalada.

Na primeira página da edição de março (Edição 729, Ano 22 Mar. 1897), coloca-se em destaque uma ilustração, que é explicada na legenda que a acompanha: "A República contempla o heroísmo dos seus defensores, na jornada de 4 , nos sertões da Bahia, em luta homerica contra os inimigos da Patria e offerta-lhes uma corôa de louros.". Para compreender e analisar o discurso textual e pictórico aqui representado é importante destacar o fracasso da Terceira Expedição oficial. Com a morte de Moreira César já no início de março, o exército oficial é obrigado a retroceder. Em relação à charge mencionada, José Murilo de Carvalho (Carvalho, 2009: 75-96) atenta para a belicosidade da personagem feminina apresentada em destaque, sendo o aspecto belicoso recorrente na arte de cartunistas do período. Na imagem que serve de capa a esta edição, a República aparece em primeiro plano portando, na mão esquerda, uma espada e uma bandeira, oferecendo uma coroa de louros com a direita, como indicado pela legenda. As expressões faciais e corporais demonstram o caráter imponente da República, personificada pela figura feminina. Em segundo plano observa-se um soldado morto, e em terceiro plano, oficiais legalistas e conselheiristas em combate. A representação do soldado morto dialoga com o trecho da legenda em que os defensores da República são novamente associados à figura de heróis e mártires. De acordo com Hermann (Hermann, 2003: 121-160), 
o desfecho inesperado da Terceira Expedição auxiliou a criar um imaginário de que os sertanejos de Canudos pareciam invencíveis. A apreensão por parte das autoridades oficiais tendo em vista o crescimento do arraial apresenta-se na revista com um discurso em busca de explicações, assim como para divulgar a imagem de uma República forte e capaz de se sustentar e combater os "inimigos da República”.

A página seguinte auxilia a compreender as questões levantadas por Hermann (Hermann, 2003: 121-160). É redigido um artigo, assinado por "L.M.", em formato de carta ao então presidente Prudente de Moraes, em que o autor aponta que um dos grandes erros do seu governo foi a anistia dos rebeldes, que propiciou a disseminação de ideais monárquicos. E para contrapor essa ideia, merece destaque o trecho a seguir:

[...] Irão outros, mais outros, muitos outros para o campo de batalha, provar a S Ex. que os heróes não morreram na nossa patria, que a República é inatacavel, que os corações brazileiros pulsam no mesmo unisono, no mesmo enthusiasmo pelas instituições de que S. Ex. foi um dos mais gloriosos paladinos. Que importa! os cadáveres de Canudos são a sementeira de uma nova éra. (Revista Illustrada, edição 729: 2)

Com a iminente derrota das forças oficiais, percebe-se uma mudança no discurso da revista, procurando acentuar as diretrizes ideológicas e políticas que a norteiam. A exaltação dos combatentes oficiais como heróis torna-se clara, seja pelo discurso escrito, ou pela disposição dos elementos presentes na ilustração. O diálogo entre os elementos escritos e pictóricos aponta para a ênfase dada à República enquanto 
protetora dos combatentes oficiais, sendo estes defensores da mesma. A personificação da República enquanto uma figura feminina demonstra uma relação de reciprocidade entre ambos. Em comparação com as edições anteriores, quase não são mencionados os "fanáticos religiosos" do sertão baiano. Nesta edição, a revista silencia as críticas acirradas aos conselheiristas, buscando ressaltar o valor da atuação dos soldados republicanos. Entretanto, a oposição entre "defensores da Pátria” e “inimigos da Pátria" continua sendo tocada.

Na página 3, o breve texto em homenagem à Moreira César, assinado por "Xavier Pinheiro", exemplifica a tentativa de construir um discurso através da memória dos grandes feitos dos "heróis republicanos”. Na página 4, o retrato do coronel Moreira César aparece acompanhado da legenda, que reforça essa ideia:

Heroico commandante da expedição contra as hordas fanáticas e sebastianistas de Antonio Conselheiro, nos sertões da Bahia, victimado pelos inimigos da Patria, no seu posto de honra, em defesa da Republica. (Revista Illustrada, edição 729: 3)

Na edição de abril (Edição 730, Ano 22 - Abr. 1897), o próprio título do artigo "Não há sebastianistas!", na página 2, representa uma ironia que no decorrer do texto é desconstruída: “A verdade é que sempre houve sebastianistas, que os há (estão ahi à vista de todos) e que deve havel-os. [...] Guerra pois a esses mascarados, a esses camaleões, a esses inimigos da Patria.”. O artigo é assinado por J. Marcio. Nas páginas 3 e 6, são publicadas duas homenagens ao general Arthur Oscar e ao 
Major Febronio, destacados como bravos combatentes durante o conflito de Canudos, o que demonstra a tentativa criar uma aproximação entre o público alvo do periódico e os "heróis da República".

Em uma breve nota da página 7, é interessante destacar o anúncio sobre a venda do retrato em avulso de Moreira César em edição especial, devido ao esgotamento da edição 729 da revista, na qual este havia sido publicado primeiramente. Uma breve análise da repercussão social a partir desses dados demonstra a resposta do público frente ao discurso veiculado. Portanto, elucida-se a partir da análise da documentação o público para o qual a revista se destinava: membros de uma classe social elitizada e politizada, por ser uma revista que reproduzia o discurso oficial.

Após essa edição, há um lapso de tempo de quatro meses em que não são lançadas novas edições. Na edição de setembro (Edição 731, Ano 22 - Set. 1897), na página 2, é emitida uma nota dirigida aos leitores, em que os editores explicam os motivos pelos quais suspenderam novas edições durante esse período, dentre eles, a mudança de endereço e "outras dificuldades". A seguir, os artigos buscam atualizar os eventos dos últimos quatro meses, narrando os acontecimentos na política, bem como em relação à Guerra de Canudos. Sobre o conflito, a revista informa que ainda é uma questão preocupante para as autoridades, referindo-se aos conselheiristas como fanáticos, e ressaltando as investidas violentas dos mesmos contra os soldados legalistas. Afirma que Conselheiro continua "resistindo aos ataques de um exército regular há três meses diante do seu reduto", e que as investidas do governo contra Ca- 
nudos estavam se fortificando com a participação do ministro da guerra no conflito. $\mathrm{O}$ artigo termina com as seguintes palavras:

Enfim, o que os verdadeiros patriotas devem desejar neste momento é que essa desgraçada lucta termine quanto antes e pela extinção desse covil de bandidos para o qual só podem olhar com carinho os inimigos das instituições do paiz. (Revista Illustrada, edição 731: 2)

Portanto, percebe-se um discurso mais carregado, tratando os conselheiristas não só como "inimigos da Pátria”, mas agora também como "bandidos". Nesse sentido, evidencia-se novamente o fato de que o discurso da revista é moldado pela realidade social em que estão inseridos seus editores, enquanto membros de uma elite intelectual.

Por outro lado, podem ser problematizadas as causas que levaram o fechamento da revista durante quatro meses. A revista alega claramente tratar-se de complicações devido à mudança do endereço, porém, não aborda as outras questões às quais somente mencionou. A revista já se encontrava em sua reta final de existência, considerando que foi definitivamente fechada em 1898. Portanto, pode-se questionar que a posição ocupada pelos seus editores no campo da imprensa estava sofrendo alterações, considerando a entrada de inovações tecnológicas na área, e que disputavam a audiência com a Revista Illustrada.

Curiosamente, a edição de outubro (Edição 733, Ano 22 - Out. 1897) trata pouco sobre a Guerra de Canudos, citando somente, na página 3, o sucesso do concerto realizado do teatro Lyrico em homenagem 
às vítimas da Guerra de Canudos. A edição concentra-se em outros assuntos políticos que os editores julgam merecer destaque.

Na última edição da revista para consulta do ano de 1897, não é possível identificar o mês de publicação. Trata-se da edição 734, que, considerando as informações descritas num artigo dedicado a Canudos e numa ilustração, bem como a sequência da numeração das edições, provavelmente foi publicada em novembro ou dezembro. Na página 5, a ilustração vem acompanhada pela legenda: "Homenagem da "Revista Illustrada" aos gloriosos vencedores de Canudos". A imagem representa a República, novamente como uma figura feminina, lembrando Marianne, figura alegórica da República Francesa, posicionada altivamente e contemplativa, enquanto homenageia um membro do exército oficial, em destaque. A República parece envolver o homem com o braço direito que segura uma folha de palmeira, enquanto o outro braço segura outra folha, uma faixa e uma coroa de louros. Na parte inferior da imagem, observam-se dois grupos de soldados. Enquanto um comemora a vitória levantando uma bandeira do Brasil, o outro grupo apresenta-se em fase de luta. No canto inferior direito, chama a atenção que um dos soldados levanta uma arma em direção a um homem caído e provavelmente ferido ou morto, que parece ser um sertanejo, devido às suas vestes. A imagem possui uma grandiosidade tipicamente utilizada para representar e comemorar uma ilustre vitória. Com o término do conflito em 4 de outubro de 1897 com a realização da Quarta Expedição oficial, quando o arraial foi incendiado e devastado, o discurso da revista apresenta uma mudança considerável. Pode-se deduzir que essa mudança se 
justifica como uma tentativa de criar um distanciamento com o passado recém-vivido e que ameaçava destruir a República. Nesse sentido, a revista parece construir uma memória histórica baseada nos feitos dos que define como heróis, em detrimento dos sertanejos de Belo Monte, os inimigos indesejáveis antirrepublicanos. $\mathrm{O}$ simples fato de proclamar a vitória da República parece elucidar o fim de um conflito, parece marcar uma página virada da história.

No artigo da página 6 , o discurso toma um viés tradicionalista ao lamentar as "perdas tão preciosas e sentidas para a família brazileira". Segundo a revista "está enfim sucumbida essa horda de bandidos que fizera do arraial de Canudos o seu quartel general, levantando a bandeira do fanatismo religioso e da restauração monarchica contra a civilização e as instituições republicanas". Realizando um breve balanço e uma análise parcial dos acontecimentos, a revista ressalta que antes da formação do arraial de Canudos, ninguém imaginara

que um ignorante miserável, um fanático imbecil, pudesse reunir tantos elementos de resistência, tão grande numero de bandidos [...] Antonio Conselheiro tudo conseguio, offerecento uma resistência tenaz, embora os seus partidarios manejassem a arma formidável da trahição, como o assassino que na estrada de emboscada fere sua victima sem ser visto. (Revista Illustrada, edição 734: 6)

A revista ainda aponta o caráter desigual da luta travada, considerando "a vantagem dos bandidos", já que estes conheciam as condições climáticas e topográficas da região. E afirma: “apesar disto a civilisação triumphon sobre a barbárie, a Republica venceu a restauração”, termi- 
nando o texto de maneira triunfal: "Honra, pois, ao nosso patriótico exercito! Viva a Republica!". Evidencia-se assim a criação de um fim ao conflito sendo declarada a "vitória" republicana, enfatizando assim o viés elitista, racista e excludente da revista.

\section{Considerações finais}

A partir da análise dos documentos foi possível estabelecer um panorama do discurso defendido pela Revista Illustrada, que é carregado de tendências políticas, inseridas num contexto histórico, social e temporal específicos. Sendo a revista destinada a um público citadino do Rio de Janeiro, que de certa forma, beneficiara-se com o processo modernizador da República, é importante acrescentar a essas questões outros elementos de análise à fonte, transformando a oposição entre os soldados "heróis" da República, e os sertanejos "bandidos", em uma concepção discursiva a ser historicizada. No presente trabalho, buscamos entender essas novas possibilidades de abordagem que vem sendo discutidas pela historiografia, realizando a partir da analise da alguns trechos selecionados da Revista Illustrada referentes a Canudos, uma análise do discurso republicano da mesma. Tendo em vista a oposição entre diversas tendências republicanas e monarquistas no período da Proclamação, atentamos para a possibilidade de dar continuidade a esses estudos para compreender a complexidade intelectual do período, e que influenciaram a reprodução em vários casos um discurso estigmatizado do movimento. 


\section{Bibliografia básica}

BONAVIDES, P.; AMARAL, R. Textos políticos de história do Brasil. Volume 3. Brasília: Senado Federal, 2002. p. 445- 450.

CARVALHO, José Murilo de. "O Rio de Janeiro e a República". In: CARVALHO, José Murilo de. Os Bestializados. São Paulo: Editora Schwarcz/ Companhia das Letras, 1991. p. 15- 41.

CARVALHO, José Murilo de. "República-Mulher: entre Maria e Marianne”. In: CARVALHO, José Murilo de. A Formação das Almas. São Paulo: Editora Schwarcz/ Companhia das Letras, 2009. p. 75- 96.

COSTA, Carlos. "O auge das revistas semanais ilustradas: 1876-1878". In: COSTA, Carlos. A revista do Brasil do século XIX. A história da formação das publicações, do leitor e da identidade do brasileiro. São Paulo: Alameda Casa Editorial, 2012. p.315 a 363.

HERMANN, Jacqueline. "Religião e política no alvorecer da República: os movimentos de Juazeiro, Canudos e Contestado". In: FERREIRA, Jorge ; Lucília de A. N. DELGADO (Orgs.). O Brasil republicano. O tempo do liberalismo excludente: da Proclamação da República à Revolução de 1930. Rio de Janeiro: Civilização Brasileira, 2003. p.121160.

LACERDA, Rodrigo. "Sobrevoando Canudos". In: ABDALA Jr., Benjamin; ALEXANDRE, Isabel. (Org.). Canudos: Palavra de Deus, Sonho da Terra. Editora Senac; Boitempo Editorial, São Paulo. 1997. p. 21- 39 .

MARINGONI, Gilberto. "Angelo Agostini e o Massacre de Canudos". In: Revista Projeto História, São Paulo, vol. 32, jun. 2006. p. 221-239, disponível em http://revistas.pucsp.br/index.php/revph/article/viewFile/2425/1515 , acesso em 7 de maio de 2015. 
MAGALHÃES, Marcelo de Souza. "Crônicas da vida na cidade: o cotidiano da política nas charges da Revista Illustrada (1892-1898)". In: Urbana, ano 2, v. 2. Dossiê: Cidade, Imagem, História e Interdisciplinaridade. CIEC/UNICAMP, 2007. p. 1-29.

SEVCENKO, Nicolau. Introdução. "O prelúdio republicano, astúcias da ordem do progresso”. In: NOVAIS, Fernando A. (Coord. Geral) História da vida privada no Brasil. Vol. 3. República: da Belle époque à era do rádio. SEVCENKO, Nicolau (Org. do vol.). São Paulo: Companhia das Letras, 1998, p. 7-48.

THEODORO, Janice. "Canudos 100 anos depois”. In: ABDALA Jr., Benjamin; ALEXANDRE, Isabel. (Org.). Canudos: Palavra de Deus, Sonho da Terra. Editora Senac; Boitempo Editorial, São Paulo, 1997. p. 119-133.

Recebido em: 07/02/2016 Aceito em: 03/10/2016 